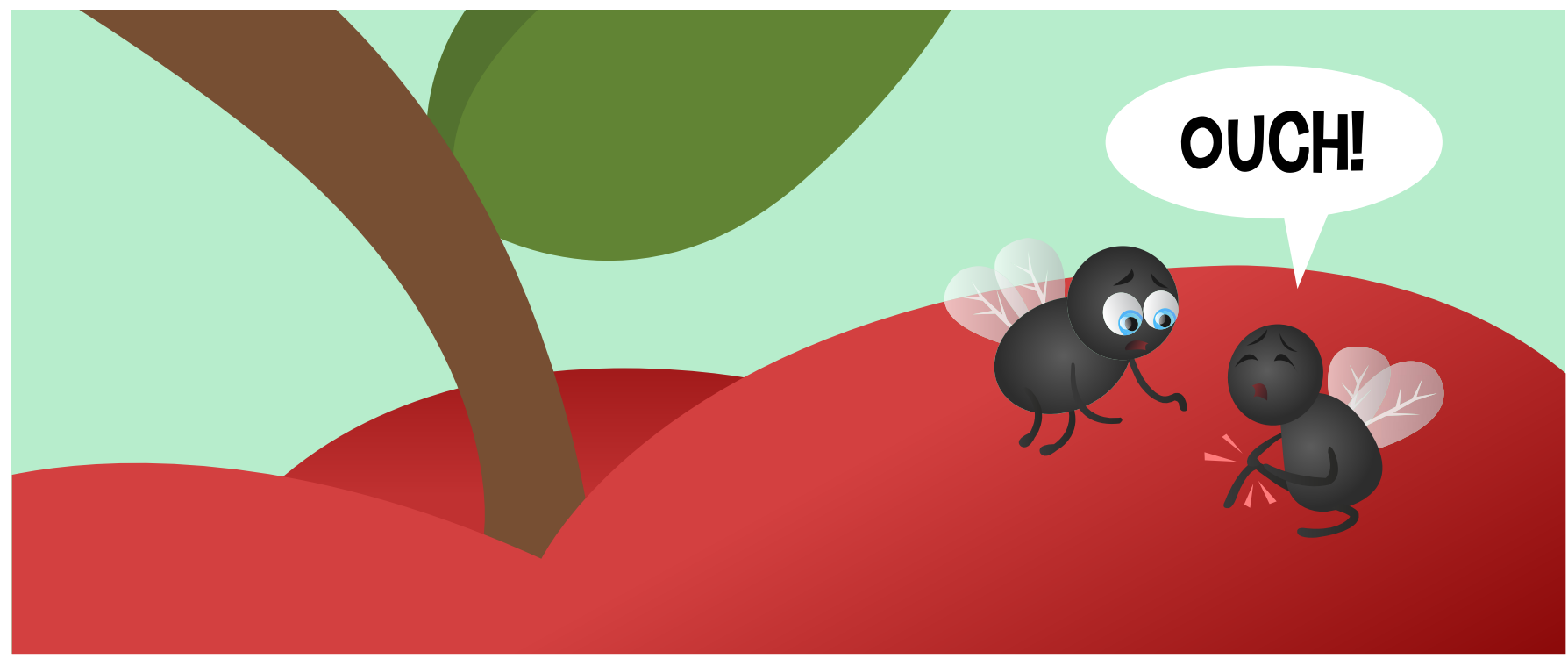

\title{
HOW DOES A FRUIT FLY SAY "OUCH"?
}

\section{Michelle T. Juarez*}

Sophie Davis Program in Biomedical Education, City College of New York, New York, NY, USA

\section{REVIEWED BY: \\ THE \\ METROPOLITAN \\ SCHOOL OF \\ PANAMA \\ 12 YEARS OLD}

\section{DEOXYRIBO- \\ NUCLEIC ACID (DNA)}

Genetic material in living organisms.

\section{GENETIC}

\section{INFORMATION}

Is the study of how changes in the DNA can affect the growth or behavior.
Fruit flies are an ideal animal for biological research. Fruit flies can grow quickly in the lab, and we can study many fruit flies at the same time. The fruit fly has an outer layer, just like the human skin, to protect itself from injury or damage. If humans and fruit flies respond to injury in similar ways, then we can use fruit flies to discover new steps to improve human health. Using small needles to wound the fruit flies, we are able to ask questions about how fruit flies repair their wounds. We wondered what kind of reaction the fruit flies would have when we injured their skin. Fruit flies are small and we used microscopes to see the wound reaction - Ouch! The goal of this research was to test whether changes in the fruit fly deoxyribonucleic acid changed the way the fruit flies responded to injury.

\section{LESSONS FROM A FRUIT FLY}

All living organisms contain deoxyribonucleic acid (DNA), which is the genetic information of an organism. What does this mean? Genetic information is similar to a blueprint for building a tree house. If the information in the blueprint is correct and the building materials are strong, then you can build a tree house that will last for a long time (Figure 1A). However, if there are directions missing or duplicated, then the tree house might fall apart. Fruit flies (Latin name: Drosophila melanogaster) are a great animal 
FIGURE 1

A comparison between A. blueprints, which are instructions to build something like a tree house, and $\mathbf{B}$. deoxyribonucleic acid, which contains instructions (genetic information) to build an animal, like a fruit fly.

\section{ENTOMOLOGY}

Is the study of insect science.

\section{ACTION/REACTION}

Injury method to study wound and pain.

\section{CUTICLE}

Outer layer in fruit flies.

\section{SKIN}

Outer layer in humans.

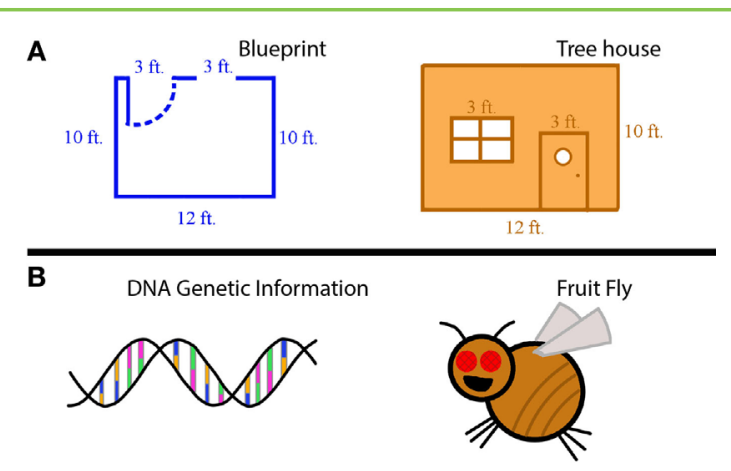

FIGURE

to use for experiments, because we can ask questions about their blueprints (DNA) to understand complex problems about the building of the tree house (the fruit fly body) (Figure 1B). Fruit flies have been used in research for over 100 years to study genes and their effects on building the fruit fly body [1]. Current research on fruit flies combines the strengths of many biological techniques with DNA data available on the computer [2]. Fruit flies are insects, and the study of insect science is called entomology.

Every living animal uses some sort of specialized outer layer to protect itself and keep the inside of the body from leaking out, and also to prevent outside dangers from hurting the body. A breakdown in this outer layer triggers a wide range of reactions in an animal. When the outer layer is damaged, the animal must immediately turn on genes that help with repair of the outer layer and turn off genes of unwanted organisms. Many problems can happen when genes are not turned on and off properly. For example, if a repair gene is in the "on" state at the wrong time, then a large scar can form. Or, if the protection gene is in the "off" state at the wrong time, then an open sore can be an entrance for unwanted organisms and infections. Therefore, the balance between wound repair and protection is important to understand.

We performed our research using action/reaction questions, meaning we performed an action on the fruit flies (injuring the fruit fly cuticle, which is similar to the skin, with a small needle) and then observed the fruit flies to see their reaction to the injury. There are several advantages to using fruit flies to ask scientific questions. Fruit flies can grow quickly in the lab (they have a 10-day life cycle, which is the time it takes for them to grow from babies to adults) and they can live for a long time (a 60-day life span, which is the total time the fruit fly is alive). Fruit flies are not expensive to grow in the lab, so we can easily use a lot of them, even 100, for each of our experiments. A disadvantage of using fruit flies is that they are small and cannot be seen without the aid of microscopes to provide a close-up view. After considering both the advantages and disadvantages, we chose to perform our experiments on fruit flies because it is hard to do similar 
experiments in humans; for example, try to find 100 volunteers to "stab" and watch their wounds heal!

Injury occurs when there is damage to the body and injuries happen many ways. Sometimes, we can see the injury if it occurs on the outside of the body. Other times, if the injury is on the inside of the body, we cannot see it. Fruit flies are so small that we can use special microscopes to help us see both the inside and outside of their bodies at the same time. In this video link (http://www.jove.com/video/50750/microinjection-wound-assay-vivolocalization-epidermal-wound-response), you can see that a small needle piercing a fruit fly makes a small injury [3]. We can ask questions about the reaction of the fruit fly to this injury. We used two different methods of causing injury: (1) needle puncture - similar to a bug bite that leaves a small sore spot your arm - and (2) injection of a chemical - similar to a poison ivy rash that causes sore spots all over your body. We used both of these methods to test the role of certain pieces of DNA in the wound reaction (WR). We were curious about why a bug bite causes a small reaction but poison ivy causes a large reaction.

We used the scientific method as a path to investigate the responses of the fruit flies to injury. The first step in the scientific method is to ask a question and think about the answer. The answer is your hypothesis. Our hypothesis was that a local reaction to injury will improve survival of fruit flies. The second step is to do the experiment, by studying action/ reaction. The actions we performed on the fruit flies are described below. The third step in the scientific method is to gather the answers from the experiment, which we did by looking at the reaction of the fruit flies to injury. The final step is to look back at the hypothesis and then repeat the experiments again. The goal of our study was to test the WR in the fruit fly and maybe try to improve it, so that the results could possibly be used to treat injury in humans [4].

\section{THE DISCOVERY}

Scientists can perform a special technique on some kinds of animals, including fruit flies, in which they can add and subtract DNA. Imagine one kind of fruit fly that has the normal amount of DNA and a normal

MUTANT

An animal with a change in its DNA.

\section{MUTATION}

The change in the DNA. cuticle (Figure 2A). Then, picture a special (or mutant) kind of fruit fly with a change (or mutation) that has had some DNA subtracted and cannot grow a cuticle at all (Figure 2B). Then, picture another special kind of fruit fly with a different mutation that has had some extra DNA added and grows an extra layer of cuticle (Figure 2C). Using techniques in the lab to make changes in the fruit flies' DNA, we did experiments using all three types of fruit flies (normal cuticle, no cuticle, and extra layer of cuticle). We examined these three types of fruit flies to see how they responded to injury. We thank the fruit flies for their service 
FIGURE 2

Different kinds of mutations can affect fruit fly cuticle. A. The normal amount of fruit fly deoxyribonucleic acid (DNA) provides genetic information to build normal fruit fly cuticle.

The area highlighted in red shows the area where changes/mutation may occur. B. When genetic information is subtracted from the area of the fruit fly's DNA that provides instructions to build fruit fly cuticle, the fly does not grow any cuticle, as shown by the dotted line. C. When genetic information is added to the area of the fruit fly's DNA that provides instructions to build fruit fly cuticle, the fly grows extra thick cuticle, as shown by the thick line.

A Complete DNA Normal Fly Skin
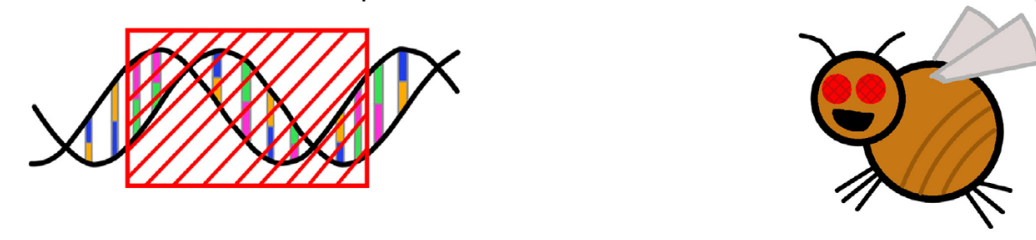

B

Subtracted DNA

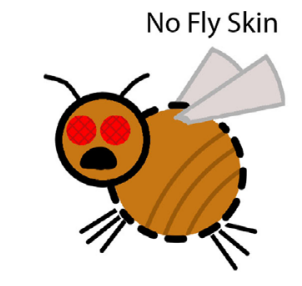

$\mathbf{C}$

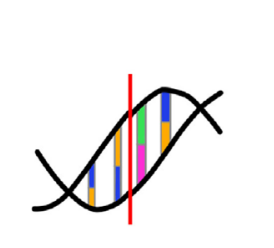

Subtracted DNA
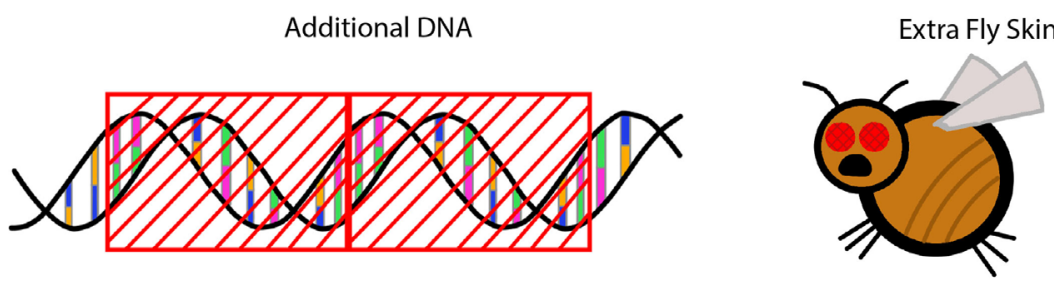

FIGURE 2

because we know that they take the place of other animals or humans in our research! In biology, the fruit fly is an awesome animal to use to ask tough questions and show us the answers.

\section{HOW DOES A DNA MUTATION CHANGE THE WOUND REACTION IN THE FRUIT FLY?}

We used an "ouch scale" to measure the reaction of the fruit flies to injury. The "ouch scale" is a series of faces that show no pain, mild pain, moderate pain, and severe pain (Figure 3A). A local WR is small reaction in the fruit fly, similar to a bug bite. We label this as mild on the "ouch scale." A global WR is a large reaction in the fruit fly, similar to a poison ivy rash. We label this type of reaction as severe on the "ouch scale." If we use the needle puncture procedure on fruit flies with the normal amount of DNA and a normal cuticle, the needle puncture injury results in a local WR, which is mild on the "ouch scale." Fruit flies with the subtraction mutation that causes them to have no cuticle respond to injury with a global WR, which is severe on the "ouch scale" (Figure 3B). Another important part of the scientific method is to repeat experimental results with different samples. We did this by using a green sample (WR-Green) and a red sample (WR-Red) that gave the same WR patterns (Figures 3B,C). Repetition of an experimental result with more than one sample is like traveling to school with a bicycle or a skateboard. The travel times are the same with either activity, but it is fun to have a choice of how to get where you are going. 


\section{FIGURE 3}

A comparison of the wound reaction (WR) in normal and mutant fruit flies. A. "Ouch scale" to measure WR. B. WRgreen, normal fly - local WR, mild ouch scale and mutant fly - global WR, severe ouch scale. C. WR-red, normal fly - local WR, mild ouch scale and mutant fly - global WR, severe ouch scale.

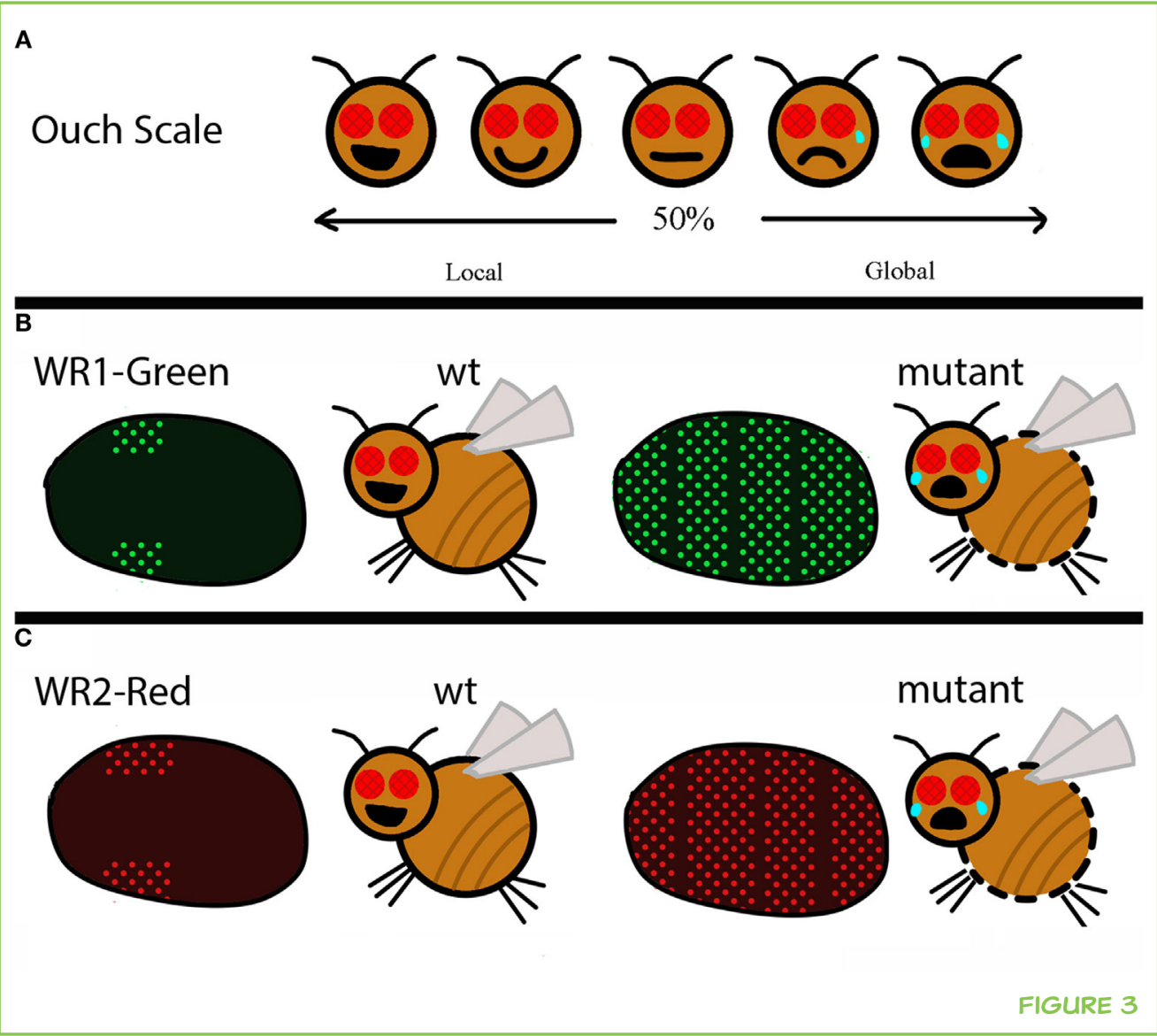

\section{HOW DOES A CHEMICAL CHANGE THE WOUND REACTION IN THE FRUIT FLY?}

Another way to study the WR in fruit flies is to inject them with a chemical solution that copies a DNA mutation. This method also allowed us to test whether fruit flies have the same WR to injuries caused in two different ways - puncture in mutant fruit flies versus chemical injection. Injection of chemical solution into a normal fruit fly resulted in a global WR, which is severe on the "ouch scale" (same as Figures 3B,C) and is the same as the fruit flies with the subtraction mutation that got the needle puncture injury. The fact that we observed the same result with a DNA mutation and a chemical injection leads to new questions about overlap between the DNA and the chemical in the WR.

These kinds of experiments have been repeated several times and in several different ways. The next step after the discovery of the changes of WR in the fruit fly is to figure out what the different genes involved in the WR might be doing. Then, additional studies can be done in other animals to see if they have the same kind of WR as the fruit flies or whether different animals use different strategies to repair their wounds. Ultimately, we hope that our results will be useful in helping humans with injuries [5]. 


\section{BUILDING A BETTER BANDAGE}

The fruit fly WR can hopefully help us to understand how many different animals, including humans, react to and heal their wounds. Injuries can have many different causes (for example, surgery or infection) and can affect different body parts (for example, skin or muscle). Understanding how animals respond to injuries and damage may give us a way to improve human health. The more we understand about the blueprints used to build our tree house, the more we can use fruit flies to improve the treatment of human injuries. In addition, because all living organisms contain DNA, we can study changes in DNA over time and ask more questions in different animals (including worms, fruit flies, and mice). Scientists who study animals help discover fun facts about biology - the science of all living things. Our ultimate goal is to understand the special connection between humans and all other living things - bacteria, fungi, plants, and animals.

\section{ACKNOWLEDGMENTS}

The research of the original article used to describe this New Discovery article was partially supported by The National Institutes of Health, NIH NIAID R03AI117671, NIH NCI U54CA137788/U54CA132378, and NIH NIMHD 8G12MD7603. Finally, the author is very grateful to Chiandredi and Chloe, for their brilliant advice and editorial input on this New Discovery article. They contributed to the drawing of the figures and the development of analogies to explain the scientific ideas. Their courage to try something new and expose a new audience to biology is refreshing.

\section{ORIGINAL ARTICLE REFERENCE}

Juarez, M. T., Patterson, R. A., Sandoval-Guillen, E., McGinnis, W. 2011. Duox, Flotillin-2, and Src42A are required to activate or delimit the spread of the transcriptional response to epidermal wounds in Drosophila. PLoS Genet. 7:e1002424. doi:10.1371/journal.pgen.1002424

\section{REFERENCES}

1. Ugur, B., Chen, K., Bellen, H. J. 2016. Drosophila tools and assays for the study of human diseases. Dis. Model. Mech. 9:235-44. doi:10.1242/dmm.023762

2. Attrill, H., Falls, K., Goodman, J. L., Millburn, G. H., Antonazzo, G., Rey, A. J., et al. 2016. FlyBase: establishing a Gene Group resource for Drosophila melanogaster. Nucleic Acids Res. 44:D786-92. doi:10.1093/nar/gkv1046

3. Juarez, M. T., Patterson, R. A., Li, W., McGinnis, W. 2013. Microinjection wound assay and in vivo localization of epidermal wound response reporters in Drosophila embryos. J. Vis. Exp. 81:e50750. doi:10.3791/50750

4. Juarez, M. T., Patterson, R. A., Sandoval-Guillen, E., McGinnis, W. 2011. Duox, Flotillin-2, and Src42A are required to activate or delimit the spread of the 
transcriptional response to epidermal wounds in Drosophila. PLoS Genet.

7:e1002424. doi:10.1371/journal.pgen.1002424

5. Sen, C. K., Gordillo, G. M., Roy, S., Kirsner, R., Lambert, L., Hunt, T. K., et al. 2009.

Human skin wounds: a major and snowballing threat to public health and the economy. Wound Repair Regen. 17:763-71. doi:10.1111/j.1524-475X.2009.00543.x

SUBMITTED: 29 June 2016; ACCEPTED: 23 November 2016;

PUBLISHED ONLINE: 13 December 2016.

EDITED BY: Pasquale Maffia, University of Glasgow, UK

CITATION: Juarez MT (2016) How Does a Fruit Fly Say "Ouch"? Front. Young Minds 4:27. doi:10.3389/frym.2016.00027

CONFLICT OF INTEREST STATEMENT: The author declares that the research was conducted in the absence of any commercial or financial relationships that could be construed as a potential conflict of interest.

COPYRIGHT @ 2016 Juarez. This is an open-access article distributed under the terms of the Creative Commons Attribution License (CC BY). The use, distribution and reproduction in other forums is permitted, provided the original author(s) or licensor are credited and that the original publication in this journal is cited, in accordance with accepted academic practice. No use, distribution or reproduction is permitted which does not comply with these terms.

\section{REVIEWED BY}

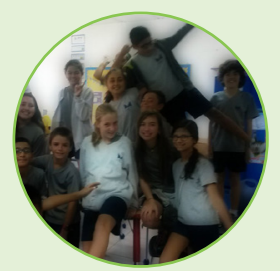

\section{THE METROPOLITAN SCHOOL OF PANAMA, 12 YEARS OLD}

We are the sixth grade class of the Metropolitan School of Panama. We are an international school, and our students come from all over the world. This year we will be learning about the scientific method and how it is used to share scientific knowledge. We are happy to be part of sharing that knowledge, editing articles for students like us to understand.

\section{AUTHOR}

\section{MICHELLE T. JUAREZ}

I am a professor at City College of New York. In my lab, we study Drosophila genetics and development to ask questions about wound repair and infection. I enjoy working with students and introducing them to the exciting world of Biology and Science. When I am not in the lab, I have fun going for walks and growing plants in my window gardens. *mjuarez@med.cuny.edu 